\title{
FERTILIZATION RATE AND EMBRYONIC SURVIVAL IN DAIRY COWS IN RELATION TO TRANSFERRIN AND J ANTIGEN GROUPINGS OF SIRES AND DAMS
}

\author{
H. BOYD,* A. JAMIESON $†$ AND J. G. HALL $\dagger$ \\ * Department of Veterinary Reproduction, University of Glasgow Veterinary Hospital, \\ Bearsden, Glasgow, and $†$ Agricultural Research Council, Animal Breeding Research \\ Organisation, Edinburgh 9
}

(Received 22nd March 1968)

\begin{abstract}
Summary. The sera of ninety-six reproductively normal cows and twenty-six artificial insemination bulls were typed for transferrin and for $\mathrm{J}$ antigen. Fertility of the cows was measured by examination of the genital tracts between 2 and 26 days after insemination at post-mortem or laparotomy. No significant relationship was observed between fertility and transferrin type or $\mathrm{J}$ antigen in these experimental animals. The results of approximately 90,000 inseminations with semen from the twenty-six bulls were also studied in relation to these types and again there was no useful association.
\end{abstract}

\section{INTRODUCTION}

Biochemical polymorphism has been widely discussed in connection with the function of many body systems (for review see Ogden, 1961). One expression of biochemical polymorphism which has been related to reproductive efficiency in cattle is the variation in serum transferrin type. Ashton (1959) considered that embryos differing in $\beta$-globulin (transferrin) type from their dams were less compatible with their dams than those with the same type as their dams, and were therefore less likely to survive. Ashton \& Fallon (1962) modified this theory in a report on data from five cow populations in Britain and Australia. It appeared that breeding efficiency was highest when mating took place between unlike homozygotes and was reduced progressively with mating between like homozygotes, homozygotes crossed with heterozygotes and lowest with heterozygotes crossed with heterozygotes. They also considered that there was a different effect on fertilization and embryonic death in that matings between like homozygotes were considered more fertile than matings between unlike homozygotes while heterozygous embryos were considered more viable than homozygous ones. These hypotheses were based on field fertility data and blood grouping for bulls and cows. Gahne (1967) has summarized the results of these and other workers in a recent study of the influence of transferrin variation on fertility in Swedish cattle. The present authors examine similar data but

¥ Present address: Sea Fisheries Laboratory, Ministry of Agriculture, Fisheries and Food, Lowestoft. 
recognize a fourth allele at the transferrin locus. This allows the test of heterozygous versus homozygous effect to be made with more precision. They also examine the influence of the $\mathrm{J}$ blood group system.

Following the valuable and extensive work of Stone (1956), Jamieson, reading a paper on J phenotypes in relation to conception rates at the ImmunoGenetics Conference in Edinburgh, classified cattle into two qualitative types using the $\mathrm{J}$ antigen. There was one group in which varying amounts of soluble $\mathrm{J}$ antigen were detected in the serum and another in which the absence of $\mathrm{J}$ antigen was confirmed when they produced $\mathrm{J}$ antibody in some circumstances. Jamieson (1960) suggests that since $J$ antibody in the serum of one phenotypic class is capable of reaction with $J$ antigen dissolved in the body fluids of the other it may be worth looking for conception rate differences. Cows capable of producing natural $\mathrm{J}$ antibody would perhaps show a reproductive disadvantage when inseminated with $J$ antigen semen or caused to conceive potentially $\mathrm{J}$ antigen embryos. It is possible, however, that the great dilution of semen which takes place in artificial insemination would reduce the importance of this factor.

\section{MATERIAL AND METHODS}

This was part of a study of embryonic death in dairy cattle in which 112 reproductively normal Ayrshire cows were inseminated under good field conditions. The semen used was from the local artificial insemination centre and was freshly collected from bulls of known good fertility. Some of the 112 matings were not included in this report because either the cows or the bulls were not typed or they were typed before the distinction was known between $\mathrm{Tfd}^{1}$ and $\mathrm{Tfd}^{2}$.

The cows were slaughtered or subjected to laparotomy at various stages after insemination and the genitalia were examined for the presence of an ovum or embryo. In cows examined 2 to 4 days after insemination, the oviducts were flushed with saline or serum and ova detected by low power microscopy. In cows killed at 12 to 16 days after insemination, the uterus was flushed with normal saline and the conceptus recovered. In those animals which were slaughtered at the 25 th or 26 th day after insemination, detection of the embryo was by dissection of the uterus.

Venous blood was collected from the cows and bulls and the serum stored at $-20^{\circ} \mathrm{C}$ until a batch could be sent to the laboratory where it was typed for transferrin and $\mathrm{J}$ antigen phenotypes by the following methods.

Tests for transferrin types

The methods for testing and identifying bovine transferrin types were as described by Jamieson (1965).

\section{Tests for $\mathcal{Z}$ type}

The $\mathrm{J}$ factor in serum was detected by its ability to inhibit the specific haemolytic reaction of a standardized dilution of $J$ antibody with a standardized source of J antigen. The tests were made in tubes of $25 \times 7 \mathrm{~mm}$ internal diameter. 
Glass Pasteur pipettes calibrated to deliver twenty or twenty-one drops from $0.3 \mathrm{ml}\left(15\right.$ or $14 \mathrm{~mm}^{3}$ ) of saline were used to dispense reagents. Each tube received four drops. The first drop was of test serum undiluted, to be followed in nine other tubes by a series of doubling dilutions with $0.9 \%$ sodium chloride. The second drop to each tube was of the standardized J antibody in an appropriate dilution sufficient to haemolyse the test erythrocytes. The third drop was of an approximately $1.5 \%$ suspension (by eye and experience) of thrice-washed erythrocytes from a cow MZ111B of known $\mathrm{J}$ antigen properties which had been used extensively over 4 years in routine $J$ antigen tests.

The fourth drop was of rabbit haemolytic complement. This was used undiluted, pooled from twenty rabbits selected as having very low naturallyoccurring anti-ox antibodies, but further absorbed at $+4^{\circ} \mathrm{C}$ in the proportion of four parts serum to one part packed red cells from the standard J positive cow.

$\mathrm{J}$ antibody was detected separately by direct haemolytic tests as above, but omitting the second drop so that three drops were used: test serum, red cells and complement.

Sera from cattle with known $\mathrm{J}$ antigen properties were included in all tests as controls.

The serological reactions were conducted at a room temperature of 16 to $19^{\circ} \mathrm{C}$ in racks which were mechanically agitated overnight for 30 to $60 \mathrm{sec}$, at intervals of $1 \mathrm{hr}$, for $6 \mathrm{hr}$. The unlysed erythrocytes were allowed to settle before the tests were read next morning.

The strength of the $\mathrm{J}$ antigen in each serum was indicated by the dilution at which it inhibited the haemolysis of the test cells by the standard anti-J.

The presence of anti- $\mathrm{J}$ in the test sera was indicated by the lysis of the test cells in the direct test and the reciprocal failure to inhibit the standard anti-J.

\section{RESULTS}

\section{Transferrins}

In the cows in this study, there were present all ten possible transferrin genotypes known in Britain from the four genes, $\mathrm{Tf}^{\mathrm{a} 2}, \mathrm{Tf}^{\mathrm{d} 1}, \mathrm{Tf}^{\mathrm{d} 2}$ and $\mathrm{Tf}^{\mathrm{e}}$, while in the bulls nine of the ten were present. Of the 100 possible combinations between sire and dam, forty-five occurred in the ninety-five matings which were typed. Accordingly, the numbers in the different groups were small and it has been necessary to group the data as described by Ashton \& Fallon (1962) into matings between unlike homozygotes, between like homozygotes, between homozygotes and heterozygotes, and between heterozygotes (Table 1). The expected number (EC1) of conceptions was obtained by multiplying the number of inseminations in each transferrin type group by the conception rate figure given by Ashton \& Fallon (1962) for that group. At first sight these expected values bore no relation to the obtained values but as the total number of expected conceptions was 48.5 compared with an obtained number of 69 it was felt necessary to obtain a second expected value (EC2) by multiplying EG1 by $69 / 48 \cdot 5$. This resulted in a fairly close relationship between EG2 and the numbers of conceptions obtained. However, before concluding that these 


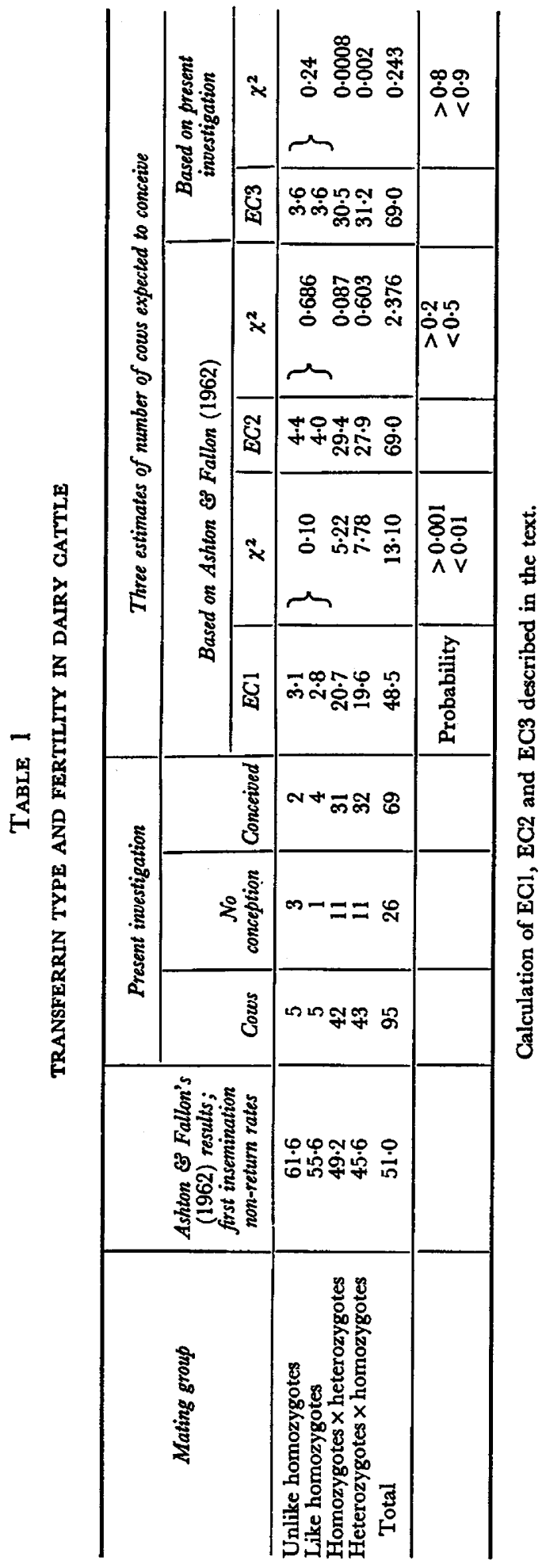


results support Ashton \& Fallon's hypothesis a third expected value (EC3) was worked out from the total number of animals conceiving (69) of the 95 which were inseminated. EG3 is the number of inseminations in a group $\times 69 / 95$. As EC3, indicative of random distribution, fitted the results obtained slightly better than EG2, there is no indication that the transferrin type affected fertility.

Ashton \& Fallon (1962) suggest that there is a different effect of transferrin type combinations of fertilization and embryonic death. Accordingly the present data were studied in relation to the length of interval between insemination and slaughter, but no clear effect was observed.

The information from the experimental cows is limited and to obtain more data, non-return conception rates from the two artificial insemination centres

\section{TABLE 2}

NON-RETURN RATE TO FIRST INSEMINATION FOR BULLS OF DIFFERENT TRANSFERRIN TYPES

\begin{tabular}{c|c|c|c}
\hline Transferrin type & No. of bulls & Inseminations & $\%$ non-returns \\
\cline { 2 - 3 } & 1 & 5,190 & $69 \cdot 0$ \\
$\mathrm{a}_{2} \mathrm{a}_{2}$ & 5 & 28,237 & $70 \cdot 0$ \\
$\mathrm{a}_{2} \mathrm{~d}_{1}$ & 3 & 13,146 & $69 \cdot 9$ \\
$\mathrm{a}_{2} \mathrm{~d}_{2}$ & 2 & 2,584 & $69 \cdot 8$ \\
$\mathrm{a}_{2} \mathrm{e}$ & 1 & 2,102 & $70 \cdot 7$ \\
$\mathrm{~d}_{1} \mathrm{~d}_{1}$ & 8 & 29,748 & $69 \cdot 8$ \\
$\mathrm{~d}_{1} \mathrm{~d}_{2}$ & 1 & 129 & $74 \cdot 4$ \\
$\mathrm{~d}_{1} \mathrm{e}$ & 5,440 & $65 \cdot 9$ \\
$\mathrm{~d}_{2} \mathrm{~d}_{2}$ & 3 & 3,560 & $67 \cdot 6$ \\
$\mathrm{~d}_{2} \mathrm{e}$ & 2 & 90,136 & $69 \cdot 5$ \\
Total & 26 & & \\
\hline
\end{tabular}

\begin{tabular}{|c|c|c|c|}
\hline Source of variation & $d . f$. & $\chi^{2}$ & $P$ \\
\hline $\begin{array}{l}\text { Homozygotes } v \text {. heterozygotes } \\
\text { Between genotypes } \\
\text { Between bulls within genotypes }\end{array}$ & $\begin{array}{r}1 \\
7 \\
17\end{array}$ & $\begin{array}{r}12 \cdot 7 \\
115 \cdot 6 \\
274 \cdot 5\end{array}$ & $\begin{array}{l}>0.2 \\
>0.2 \\
\ll 0.001\end{array}$ \\
\hline
\end{tabular}

where the bulls were standing, were examined for a 3-year period, 1961-63 inclusive. From the data in Table 2, it will be seen that there is no tendency for the heterozygous sires to have poorer conception rates than the homozygous groups. In fact, the total for the three homozygous groups gives a lower conception rate $(68.0 \%)$ than the corresponding figures for the heterozygous bulls $(68.9 \%)$. A chi-square test for heterogeneity ascribed significant differences in conception rates to individual bulls and not to transferrin genotypes.

\section{$\mathcal{F}$ antigen}

In Table 3, the fertility levels attained with the $\mathrm{J}$ antigen types of sires and dams are shown. The bulls with no $\mathbf{J}$ antigen reactions exhibited a slightly higher level of fertility than the J-positive bulls. This difference was noted in 
both the embryo survival groups and the fertilization rate groups, and was consistent over all groups of cows but was not statistically significant. The cow conception rates showed only trivial departures from expectation. In particular, there was no indication that $\mathrm{J}$ antigen-positive semen, or conceptuses were resented by $\mathrm{J}$-negative cows. Any such effect is evidently not sufficiently marked to be detectable in this data.

\section{TABLE 3}

J ANTIGEN AND GONGEPTION RATE IN DAIRY GATTLE

\begin{tabular}{|c|c|c|c|c|}
\hline \multirow[b]{3}{*}{ Cows J type $\begin{array}{c}J \text {-negative } \\
J \text {-positive }\end{array}$} & \multicolumn{4}{|c|}{ Bull's $\mathcal{F}$ type } \\
\hline & \multicolumn{2}{|c|}{$\begin{array}{c}\mathcal{F} \text { negative } \\
\text { present absent }\end{array}$} & \multicolumn{2}{|c|}{$\begin{array}{c}\mathcal{7} \text { positive } \\
\text { present absent }\end{array}$} \\
\hline & $\begin{array}{r}7 \\
21\end{array}$ & $\begin{array}{l}0 \\
4\end{array}$ & $\begin{array}{l}13 \\
38\end{array}$ & $\begin{array}{r}6 \\
18\end{array}$ \\
\hline
\end{tabular}

Contingency $\chi^{2}$ for 3 degrees of freedom $=1.34$. $P$ lies between 0.7 and 0.8 .

The field conception rates for the twenty-five bulls which were typed are presented for the 3-year period 1961-63 (Table 4). In this account of nearly 90,000 inseminations no marked difference between the groups can be seen. Presumably the difference between the bull classes in Table 3 was a local effect without significance.

Detailed results have been lodged in the library of The University of Glasgow Veterinary Hospital, Bearsden Road, Bearsden, Glasgow, and will be sent on

TABLE 4

NON-RETURN RATE TO FIRST INSEMINATION FOR BULLS OF DIFFERENT J ANTIGEN TYPES

\begin{tabular}{l|c|c|c}
\hline J antigen & No. of bulls & $\begin{array}{c}\text { No. of } \\
\text { inseminations }\end{array}$ & \% non-returns \\
\hline Absent & 9 & 30,564 & $69 \cdot 5$ \\
Present & 16 & 58,591 & $69 \cdot 9$ \\
Total & 25 & 89,155 & $69 \cdot 7$ \\
\hline
\end{tabular}

request. These data consist of transferrin and $\mathrm{J}$ antigen types of the cows and bulls and the presence or absence of conception at slaughter, between 2 and 26 days after insemination.

\section{ACKNOWLEDGMENTS}

The investigation was supported by a grant from the Agricultural Research Council, London. We wish to thank Mr A. Campbell, Mr J. Isbister and Mr J. Swanney of the Scottish Milk Marketing Board's artificial insemination centres for their help and co-operation, and members of the A.R.C. Unit of Statistics, who kindly performed the statistical tests. 


\section{REFERENCES}

Ashton, G. C. (1959) Globulin polymorphism and early foetal mortality in cattle. Nature, Lond. 183, 404.

Ashton, G. C. \& Fallon, G. R. (1962) $\beta$-Globulin type, fertility and embryonic mortality in cattle. 7. Reprod. Fert. 3, 93.

Gahne, B. (1967) Transferrin variation in Swedish cattle: Segregation and influence on fertility. Acta agric. scand. 17, (4) 185.

Jamieson, A. (1965) The genetics of transferrins in cattle. Heredity, 20, 419.

OGDen, A. L. (1961) Biochemical polymorphism in farm animals. Anim. Breed. Abstr. 29, 127.

Stone, W. H. (1956) The J substance of cattle. III. Seasonal variation of the naturally occurring isoantibodies for the J substance. F. Immun. 77, 369. 